\title{
Computing Capabilities of Knowledge Workers in the Kuwaiti Health Sector
}

\author{
Sajjad ur Rehman, Abdus Sattar Chaudhry \\ Kuwait University, Kuwait City, Kuwait \\ Email: rehman05@gmail.com
}

How to cite this paper: Rehman, S. and Chaudhry, A.S. (2017) Computing Capabilities of Knowledge Workers in the Kuwaiti Health Sector. Open Access Library Journal, 4: e3504.

https://doi.org/10.4236/oalib.1103504

Received: March 8, 2017

Accepted: April 30, 2017

Published: May 3, 2017

Copyright $\odot 2017$ by authors and Open Access Library Inc.

This work is licensed under the Creative Commons Attribution International License (CC BY 4.0).

http://creativecommons.org/licenses/by/4.0/ (c) (i) Open Access

\begin{abstract}
Knowledge workers in health care can function well in their clinical and professional practice if they have adequate computing capabilities and they apply them optimally in their work setting. Health information systems (HIS), patient health records (PHR), health databases, health portals, etc. are becoming the essential work-context for these knowledge workers. These professionals have to be equipped with relevant IT competencies in order to be usefully functional, productive and value-driven. HIS was implemented in 2006 in one of the major public hospitals in Kuwait. Thus far the system is partially functional and many of its strengths are not adequately exploited. The Purpose of this study was to examine whether health professionals possess needed computing capabilities and what role did these play in the optimization of the HIS. We conducted a survey administering a questionnaire to a stratified random sample of 210 knowledge workers. We received 130 responses and analyzed data using 124 of the usable responses. In this paper we have reviewed perceptions about the computing capabilities of these professionals, inadequacies they had reported, problems they had encountered, and the role of IT unit in the organization.
\end{abstract}

\section{Subject Areas}

Sociology

\section{Keywords}

ICT Skills, Health Workers, Healthcare, Kuwait, Hospitals, Health

Information System

\section{Introduction}

Hospitals, clinics, laboratories, healthcare systems, patient electronic records, and other supporting units are vital segments in the success of healthcare servi- 
ces in a given context. Health professionals are responsible for providing qualitative and evidence-based clinical services. ICT applications have been the cornerstone in creating health care systems and services. Health informatics, as a discipline, makes sure that the health care professionals are best equipped with seamless stream of knowledge and skills related to computing. Health Information Systems (HIS) have been instrumental in this rejuvenation of health practices and corresponding health services. Capabilities and roles of knowledge workers in the health institutions are critical in managing health services effectively [1]. Deployment of ICT has resulted in automated systems that work in integrated and networked environment in hospitals. Health professionals are responsible for clinical care, nursing, dentistry, pharmacy, public health, occupational therapy, physical therapy and biomedical/medical research, and alternative medicine.

Kuwait, an affluent Middle Eastern nation, has developed an elaborate health infrastructure to ensure its citizens' wellness. During the last few decades, Kuwaiti public hospitals have undergone fundamental transition, primarily due to the ICT applications in the health sector, resulting in widespread developments and adoption of health information systems. It is considered a national obligation that knowledge workers working in professional positions in these hospitals are best equipped with information and knowledge competencies.

Most hospitals in Kuwait have automated their functions and services in a fragmented or piecemeal manner. An optimally functional HIS is targeted in major public hospitals in the country. However, effective use of the information systems in these hospitals is possible if knowledge professionals have the essential computing and information capabilities.

There is a need to examine whether these professionals have the computing capabilities needed to work with these systems. This study was conducted with this in view. It aimed to assess the preparedness of professionals in their computing competencies. One of the major hospitals-Jahra Hospital-that pioneered in the development of HIS was selected as the locale of this study. It was premised that the information system developed here could be gainfully exploited if the knowledge professionals have the need computing skills.

Following understandings serve as conceptual parameters for the study:

1) HIS is the need of present day hospitals for their effective management.

2) IT skills are the antecedent capabilities for the use of HIS.

3) Formal training is instrumental in developing capabilities.

4) Management and IT support are critical for the implementation and use of HIS.

5) Capabilities are significantly associated with performance of employees.

6) Clinical staff (doctors, nurses, pharmacists, etc.) managers, IT professionals, medical technologists, and clerical staff are the stakeholders in the use of HIS.

This description has been the guiding imperative for assessing computing skills of the health workers and the probable approaches and strategies for im- 
proving these capabilities.

\section{Research Questions}

The study addressed the following research questions:

1) What are the ICT skills of the professional workforce of the Hospital in the use of HIS?

2) What is the extent of possession of ICT skills among the professional workforce in the hospital?

3) What training opportunities were provided to the professional workforce in the use of HIS?

4) Which problems did the professionals face in the use of ICT in the hospital?

\section{Definitions}

Health information system is a set of components and procedures organized with the objective of generating information, which will improve health care management decisions at all levels of the health system. In this study, the term HIS is used for the system named HIS in Jahra Hospital used under the directives and control of the Ministry of Health, State of Kuwait.

The term HIS capabilities is synonymous with HIS skills and HIS abilities. In this study, it refers to the capacity of health workers in Jahra Hospital in the use and functioning of HIS.

Health workers refer to health professionals in this study. This term refers to all those employees of Jahra Hospital who have been engaged in the provision of health services. These include medical and clinical professionals, managerial, technical, and data entry staff. Since these health workers are engaged in knowledge-intensive information activities, the terms information worker and knowledge worker are used synonymously.

\section{Literature Review}

In this section, we have reviewed a body of research and writings concerning values, pertinence, and use capabilities of IT in healthcare environment. Recently many studies have appeared about different aspects. Ibrahim et al. found that developments in the areas of ICT have positively impacted patient management and the training and retraining of healthcare providers. They reviewed the knowledge and utilization pattern of information technology among health care professionals in a university teaching hospital in Nigeria. Self-structured pretested questionnaires were administered to a randomly selected group of 180 health care professionals. Forty-four percent participants had received some form of computer training while the remaining $46 \%$ had no training. Only 39 respondents (26\%) owned a computer while the remaining $109(74 \%)$ had no computer. More than $18 \%$ demonstrated a good knowledge of computers while $58.8 \%$ had average knowledge. While $27 \%$ of doctors had good computer knowledge, only $4.3 \%$ of the records officers demonstrated a good knowledge. They concluded that structured training in IT was necessary for health professionals 
to take advantage of Health Information Systems [2].

In another study, Haux noted that Hospital Information Systems (HIS) have transformed over time and data handled by HIS is no more restricted to patient care and administrative purposes. Rather it covers health care planning as well as clinical and epidemiological research. There is a shift from focusing mainly on technical HIS problems to those of change management as well as of strategic information management. These systems now deal with both numeric data and images and data on the molecular level. A steady increase was found in ubiquitous computing resources and sensor-based technologies for health monitoring. A need was evident for appropriate knowledge of HIS and computing skills among health professionals. In view of the complexities of HIS, research covers the development and investigation of appropriate trans-institutional information system architectures, adequate methods for strategic information management, modeling and evaluating HIS [3].

Expounding on the value and benefits, Kimaro noted that ICT in the health sector had been implemented to help manage resources, increase efficiency, increase work productivity and reduce/workload. However, introduction and use of ICT could be problematic due to failures or unsustainability resulting from many factors. One important factor was lack of appropriate human resources. Kimaro emphasized that human resource capacity building was an urgent issue in order to ensure sustainability of ICTs. He analyzed challenges related to human resources in health information systems (HISs) and ICTs in the health sector of Tanzania and suggested some strategies to address the problem. He focused on initiation of ICT base in the context of health sector and argued for human resources with a mix of skills to understand the use of computers for building and managing HIS [4].

In another study, Schaper and Parven suggested that health professionals were reluctant in accepting and utilizing information and communication technologies. They further stated that this has contributed to a lag in adoption of ICT in the health sector. In their view, there was a need to develop and gain empirical support for models of technology acceptance in health institutions. Also there noted a need for examining utilization of technology among health professionals that might improve the success of system implementation in health services. Their study focused on ICK skills among occupational therapists in Australia [5].

Concurrently, Ajuwan and Rhine assessed Internet access, use of electronic resources, and ICT training among health professionals, using a self-administered questionnaire. Out of one hundred and twenty-one participants, slightly less than two-thirds (61.2\%) had learned ICT use through self-teaching while $70.2 \%$ had not received any formal training whereas more than $88 \%$ stated that they required ICT training. The researchers stressed the need for continued training in the use of ICT for health professionals. They suggested that training should focus on reaching all levels of potential users so that they were able to acquire necessary knowledge and skills. Such sustained efforts by all the princi- 
pal stakeholders are expected to foster the environment that is necessary for harnessing ICT potential in the delivery of health information [6].

In Barcelona, Lupiáñez et al. studied pharmacists' utilization of information and communication technology (ICT) in developing and characterizing a typology of CPs' utilization of ICT and in identifying factors that could enhance the use of these technologies. They carried out an online survey of 7649 members of the Pharmacist Association and revealed two profiles of adoption of ICT. The first profile (40.75\%) represents CPs who place high emphasis on ICT within their practice. This group referred to as integrated $\mathrm{CPs}$. The second profile (59.25\%) represented CPs who made less use of ICT and they were found to be non-integrated CPs. They noted that integration of ICT within CPs' practices could not be adequately understood and appreciated without examining how CPs used ICT in their practice, considering their organizational context and the nature of the pharmacists-client relationship [7]. In a follow-up, Larrrauri (2014) highlighted the following IT skills for this community: access to health science information, management of health information and knowledge, generation and dissemination of health knowledge [8].

It is quite noteworthy that the European Commission (EC) also acknowledged the challenges in meeting healthcare demands by adopting skill needs for health professionals. In relation to technologies, the Action Plan for the EU Health Workforce indicated that growth of new technologies was leading to a new form of healthcare delivery, which required technical and e-skills [9]. Traver et al. provided an overview about the state of the art about education of IT skills for healthcare workforce in the EU and USA, making a specific analysis about the current educational programs from different perspectives of technologies, users and IT skills. They emphasized the need for creating awareness about the importance of transnational IT educational program for the EU-US healthcare workforce [10].

In Nigerian context of a developing nation, Onadipe, Onafowokan, and Adegbite investigated the application of ICT for health information management (HIM) and the proficiency of health workers. They found that more than 95\% health workers used ICT for communication and research activities. However, use of ICT for HIM was on the lower side. The results on the proficiency of the health workers indicated that only $7.78 \%$ of health workers were found to be proficient, $21.78 \%$ were not proficient and $71.23 \%$ were indifferent to computer systems for HIM. They recommended that the government should implement ICT applications in all health facilities making ICT training compulsory for health workers They were expected to develop a range of new skills; technical and social. It was found that ICT skills enhanced communication processes among patients and health providers. ICT skills enabled greater interaction between health personnel and patients through email, SMS, chat, forums, websites, Facebook, Twitter and other media. ICT skills were related to accessing health science information, management of health information and knowledge, and generation and dissemination of health knowledge. The development of the new ICT skills required that people were digital literate [11]. 
In another Nigerian study, Adeleke et al. reviewed the use of ICT and stated that lack of effective health information management systems could impede decision-making effectiveness in healthcare. They examined the information technology (IT) skills, utilization, and training needs of health information management professionals. They deployed a cross-sectional structured questionnaire to determine the IT skills and training needs of health information management professionals who had leadership roles in national healthcare information systems. It was found that ownership of a computer, level of education and age were associated with knowledge and perception of IT. A vast majority of participants (98.8\%) acknowledged the importance and relevance of IT in healthcare information systems and many of them expressed desire for further IT training. Government intervention in the provision of IT infrastructure in order to put into practice a computerized healthcare information system would therefore be a worthwhile undertaking [12].

This review has brought forth some vital understandings about ICT with regard to the aspects of significance, relevance, skills, use, possession, training and development strategies. Across the board, similar findings prevailed at global, regional and national levels. We have noted that none of studies reviewed in this section pertained to the health workers in Arabian Peninsula in particular and Middle East in general. It further signifies the need for the conduct of this study.

\section{Procedures}

Jahra Hospital, Kuwait functions is a public hospital working under the Ministry of health. This is the largest health utility in the area. It is also one of the three public hospitals that have implemented the same health information system. However, this hospital lags behind in the implementation of the system and a number of modules had yet to be applied at the time of study. One contributing factor could be the computing skills of the health professionals of the hospital.

We designed the questionnaire around the questions of the study. It was pretested, using six faculty members of the College of Social Science. Their input was valuable for improving the questionnaire. It was estimated that it would take 20 - 25 minute of a respondent in answering the research instrument.

We administered a questionnaire for collection of data at Jahra Hospital, Kuwait. Those who participated in providing input included managers, doctors, dentists, pharmacists, nursing staff, paramedical staff, ICT and health information personnel, and other staff members who were the users of the system. We used proportionate stratified random sampling for the selection of participants. We obtained lists of employees from the hospital management. Following four strata were identified: 1) professional doctors, dentists, pharmacists, etc., 2) nursing and paramedical staff, 3) managerial and professional staff, and 4) others who entered data and performed HIS jobs. There were 210 staff members in the hospital at the time of the study.

We distributed questionnaires to 210 employees of the Hospital. We sent reminders to those who did not respond. Hospital management also sent a re- 
minder, encouraging the participants to respond to the questionnaire. With all these efforts, we received 130 filled-in questionnaires, of which 124 were usable for data entry and analysis.

\section{Findings}

\subsection{Computing Capabilities and Use}

This study report the awareness, use, and related issue of the HIS at Jahra Hospital. Considering the importance of knowledge, capabilities, training, and frequency of use of computing facilities, this study first addressed this aspect of respondent expertise. Without having adequate computing capabilities, HIS use and applications become formidable. In this section, we have presented an analysis of different aspects of computing capabilities of the respondents.

We asked the respondents how frequently they used computers at home. They responded on a 1 - 5 scale about frequency of use. A mean score of 3.67 with the standard deviation (SD) of 0.949 indicated that a majority of respondents had positively rated on the scale. The SD score indicates diversity of responses. These scores are somehow indicative of lack of consistency in the use of computing facilities among respondents.

\subsection{Use of Computer Applications}

A relevant question was investigating the extent of use of those computer applications that are widely used in official business of hospital employees. The extent of use was measured on a scale of $1-5$. Table 1 gives a descending list of these applications by their mean score. Two applications that received the mean scores of 3.29 and 3.14 were related to Internet browsing and document creation using word processor. Next two applications on the list were PowerPoint presentation and spreadsheet, having the mean scores of 2.49 and 2.24, indicative of their modest use. The two activities that received low score for their extent of use were database searching (1.97) and designing with Photoshop (1.77).

We examined frequency counts for the use of these applications. 76, 68, 35 and 32 participants marked weak or fair use respectively for database searching, spreadsheet, Internet searching, and word processing. Few of them marked very good or excellent. Apparently their use of these applications was either rare or seldom.

Table 1. Use of applications $\mathrm{N}=107$.

\begin{tabular}{ccc}
\hline Applications & Mean & SD \\
\hline Internet browsing & 3.29 & 1.405 \\
Word processor & 3.14 & 1.299 \\
PowerPoint Presentation & 2.49 & 1.422 \\
Spreadsheet & 2.24 & 1.250 \\
Database searching & 1.97 & 1.069 \\
Designing with Photoshop & 1.77 & 1.073 \\
\hline
\end{tabular}




\subsection{Possession of Computing Gadgets}

It was pertinent to find out how many of the respondents possessed computing gadgets. This is a useful indicator of their amount of interest in these gadgets. It is probable that those who owned them should have been keen in their use. We found that more than half of them (53.8\%) possessed laptops. Another $37 \%$ had PC whereas only $8.4 \%$ had smart phones. The respondents should have possessed multiple gadgets. Overall, this is an indication that a large number of respondents did not have personal possession of these electronic tools.

It was pertinent to examine the use of gadgets the respondents possessed. As expected, smart phone topped the list with the mean score of 4.04, followed by laptops and PCs with respective mean scores of 3.92 and 3.44. Use of tablets appeared to be the last item. Normally use of smart phones and tablets could be expected to be close to each other. A summary of use is given in Table 2 .

\subsection{Computing Skills}

Table 3 shows the extent of proficiency in five most relevant computing skills. Mean scores for all the five skills were found to be less than 3; implying that in general this community of respondents does not feel that they are competent in these basic skills. Operating system topped the list with a mean score of 2.95 . Thirty-four respondents marked it on the lower side of the side-indicating a weakness. Solving hardware and software problems were the weakest skills with respective mean scores of 2.19 and 1.8. Ninety and 77 respondents had marked the lowest points of the scale. Moderate skill level was marked for the two skills of using help menu and understanding of hardware devices. Still 52 and 58 respondents perceived their skill levels for the two competencies to be on the lower side. In general, these respondents had poor or weak skills.

\subsection{Perceptions about Computing Skills}

Another question pertained to the perceptions of respondents about their level

Table 2. Use of computing gadgets $\mathrm{N}=113$.

\begin{tabular}{ccc}
\hline Variable & Mean & SD \\
\hline Using Smart Phone & 4.04 & 1.407 \\
Using Laptops & 3.92 & 1.119 \\
Using Personal Computer & 3.44 & 1.321 \\
Using Tablets & 2.76 & 1.661 \\
\hline
\end{tabular}

Table 3. Computing skills $\mathrm{N}=119$.

\begin{tabular}{ccc}
\hline Skill & Mean & SD \\
\hline Using operating system & 2.95 & 1.260 \\
Solutions from help menu & 2.67 & 1.136 \\
Understanding hardware devices & 2.56 & 1.147 \\
Solving software problems & 2.19 & 1.078 \\
Solving hardware problems & 1.80 & 0.966 \\
\hline
\end{tabular}


of confidence in computing skills. They were given the five choices of being confident, nervous, afraid of making mistakes, confused about the use of computers, and avoiding their use. The respondents had to mark one of the choices. It is revealing that $90 \%$ perceived that they were confident in the use. Only 12 of them marked other choices. It means that by-and-large the users were not anxious, afraid or nervous about computers. Keeping in view that computers have become commonplace and employees have to use them in their personal or official business to a certain extent Table 4, it should be making them comfortable and confident about computing displays frequencies and percentages.

We asked respondents to indicate the frequency with which they encountered specific problem in the use of HIS. They marked the extent of frequency on a scale of $1-5$. Four problems that received mean scores in the range of 3.08 to 3.37 were related to hardware and software malfunctions (3.37 and 3.2), time consumption (3.16), and lack of supplies (3.08). These are given in Table 5.

\subsection{Availability of IT Support}

IT unit is the primary source for problem resolution. The respondents gave their views about the IT support they received in the use of HIS. Table 6 provides mean scores and SD values for the four perceptions about IT support. The four mean scores were in the close range of 3.1 and 3.33. The respondents were positive that IT was capable to solve HIS problems. They were also easily approachable. They provided proper feedback. They were also quick in giving their response. As the range indicates, the respondents' response was lukewarm. They were not

Table 4. Perceptions about computing skills $\mathrm{N}=120$.

\begin{tabular}{cccc}
\hline Variable & Frequency & Percent & Cumulative Percent \\
\hline Confident & 108 & 90.0 & 90.0 \\
Nervous & 2 & 1.7 & 91.7 \\
Afraid of making mistakes & 6 & 5.0 & 96.7 \\
Confused about use & 1 & .8 & 97.5 \\
Avoid using computers & 3 & 2.5 & 100.0 \\
\hline
\end{tabular}

Table 5. Problems in using HIS $\mathrm{N}=118$.

\begin{tabular}{ccc}
\hline Problems & Mean & Sd \\
\hline Hardware malfunctions & 3.37 & 0.923 \\
Software malfunctions & 3.20 & 1.015 \\
Consuming too much time & 3.16 & 1.034 \\
Lack of supplies & 3.08 & 0.935 \\
Delayed response & 2.97 & 1.041 \\
Server malfunctions & 2.88 & 0.984 \\
Incorrect patient data & 2.77 & 1.068 \\
Problems in tracking transactions & 2.64 & 1.016 \\
Non-friendly interface & 2.61 & 0.972 \\
\hline
\end{tabular}


Table 6. Perceptions about IT support $\mathrm{N}=118$.

\begin{tabular}{ccc}
\hline IT Support & Mean & Sd \\
\hline IT is able to Solve HIS problems & 3.33 & 0.967 \\
IT is easy to reach & 3.27 & 1.090 \\
IT provides proper feedback & 3.19 & 0.937 \\
IT gives quick response & 3.10 & 1.040 \\
\hline
\end{tabular}

passionate or vocal in their assessment as no expression received a mean score more than 4.

IT section and IT personnel have had the most critical role in the implementation of HIS, customization of modules, maintenance of the system, troubleshooting, training of employees, and general upkeep of the system. Their role is most crucial about the system. Health workers of the Hospital had mixed assessments and reactions about the conduct of IT section. Most of them were not satisfied about the training they had received.

In the course of interviews, we asked healthcare providers in the Hospital how they perceived the performance of IT and how they wished it to be improved. Some managers and doctors were critical that the IT interventions were inadequate and inefficient. They thought that IT workers should be more competent and supportive. Personnel manager was concerned that the civil service remunerations were not enough to engage and retain competent IT professionals.

\subsection{Preparation of Staff}

The managers urged provision of intensive and useful training for better preparation of staff. There was a need of better liaison with the Ministry. One manager was of the view that IT section's performance had to be improved. There was also a need for providing Help feature with all applications of the system.

\section{Conclusions}

Admittedly computing capabilities are innately related to the use and optimal exploitation of HIS. In this study, it has been established that a large majority of health professionals in Jahra Hospital are deficient in key computing capabilities. Schaper \& Parven [5] had also noted such deficiencies despite a common realization about the worth of computing skills. These health professionals, by and large, are incapable of using operating systems and software applications competently. Clinical work is largely dependent on the use of medical databases that are accessible through global database searching systems. The professionals were found to be deficient in this fundamentally significant capability. This is in turn strongly correlated with the use of research works that provide access to the latest clinical experimentation. It can be inferred that unless the management of hospital, IT unit, and information center of the Hospital put concerted effort in an integrated manner, a significant improvement in the current state may be improbable.

We also noted that formal training is instrumental in developing information 
searching and use capabilities among health professionals. Cornet [9] had also observed that formal training can be done through workshops, hands-on demonstrations, and help features available in the HIS utilities, database searching outlets, and hospital websites. The professionals were adamant in expressing their need for formal training. The IT unit of the Hospital and its Information Center need to work collaboratively for instituting formal training facilities in different sections where clusters of healthcare professionals abound. For this purpose, management has to ensure provision of adequate resources and facilities to the providers of training.

Kimaro [4] had noted the value of computing capabilities that ensured efficacy in the use of health information systems. It is commonly understood that technicians and data input personnel could easily manage day-to-day and routine transactions of the system. But system's optimal functioning requires its intelligent use for clinical and managerial decision-making. This is the essence of evidence-based clinical work. Adeleke et al. [12] noted the same in the context of decision-making in hospitals. The professionals can undertake these value-driven initiatives when they are competent in handling information systems and services of HIS in a hospital.

Too many applications are now accessible through hand-held tablets and mobile technology. It is incumbent upon the designers of the HIS that they must develop specialized applications that the professionals can download, access, and use comfortably. This is a job of both the top executives and IT unit of the Hospital. Social media outlets also need to be integrated with these gadgets. Almost every health professional is in possession of these electronic gadgets. Their level of comfort in their use can be further streamlined on these utilities.

Health professionals are always occupied in routine daily clinical practice. Unless these health workers get a sense of empowerment in attaining a level of competence in the use of computing systems and facilities, they may not fully exploit HIS capabilities. The management of hospitals must provide opportunities where professionals have the needed incentive for working with the advanced capabilities of computing and HIS.

This study has brought forth many valuable points for developing strategies for IT competency development among health workers in this hospital. The hospital management should conduct specialized workshops for various groups, as their needs are diverse. Also the systems professionals need to conduct usability studies. Findings of such studies can be used for improving system interface, addition of tutorials, and other provisions for help and FAQ (frequently asked questions).

There is a need that the hospital management establishes rich rapport between systems staff and health workers. This will open opportunities for sustained interaction and engagement between the two groups of designers and users.

The results of this study can be generalized for the health systems and services of other public hospitals in the country. This study was limited to one hospital; yet the health professionals in the country have innate semblance with regard to 
capabilities, facilities, resources and management. This study did not cover external resources of health information. Additional studies are needed to address this gap.

\section{Acknowledgements}

The researchers acknowledge with deep appreciation funding of project OI02/12 funded by Kuwait University, Research Administration.

\section{References}

[1] Lippeveld, T., et al. (2000) Design and Implementation of Health. WHO, IRIS. http://apps.who.int/iris/

[2] Ibrahim, S.B., et al. (2004) Knowledge and Utilization of Information Technology among Health Care Professionals and Students in Ile-Ife, Nigeria: A Case Study of a University Teaching Hospital. Journal Medical Internet Research, 6, 45. https://doi.org/10.2196/jmir.6.4.e45

[3] Haux, R. (2006) Health Information Systems-Past, Present, Future. International Journal of Medical Informatics, 75, 261-281.

[4] Kimaro, H.C. (2006) Strategies for Developing Human Resource Capacity to Support Sustainability of ICT Based Health Information Systems: A Case Study from Tanzania. The Electronic Journal of Information Systems in Developing Countries, 26, 1-23.

[5] Schaper, L.K. and Pervan, G.P. (2007) ICT and OTs: A Model of Information and Communication Technology Acceptance and Utilisation by Occupational Therapists. International Journal of Medical Informatics, 76, 212-221.

[6] Ajuwon, G.A. and Rhine, L. (2008) The Level of Internet Access and ICT Training for Health Information Professionals in Sub-Saharan Africa. Health Information and Libraries Journal, 25, 175-185.

https://doi.org/10.1111/j.1471-1842.2007.00758.x

[7] Lupiáñez-Villanueva, et al. (2010) The Integration of Information and Communication Technology into Medical Practice. International Journal of Medical Informatics, 79, 478-491.

[8] Lupiáñez-Villanueva, F., Hardey, M. and Lluch, M. (2014) The Integration of Information and Communication Technology into Community Pharmacists Practice in Barcelona. Health Promotion International, 29, 47-59. https://doi.org/10.1093/heapro/das049

[9] Cornet, C. (2015) Digital Healthcare Empowering Europeans. European Federation for Medical Informatics (EFMI).

[10] Traver, V., Konstantinidis, S.T., Bamidis, P.D. and Zary, N. (2015) Analysis of EU-USA Cooperation Opportunities on IT Skills for Healthcare Workforce. Environments, $2,3$.

[11] Onadie, T.O., et al. (2013) Information and Communication Technologies and Health Workers Proficiency as a Determinant of Health Information Management: A Case Study of Health Facilities Ogun Southwestern Nigeria. American Academic \& Scholarly Research Journal, 5, 54-69.

[12] Adeleke, I.T., et al. (2015) Information Technology Skills and Training Needs of Health Information Management Professionals in Nigeria: A Nationwide Study. Health Information Management Journal, 44, 30-38. https://doi.org/10.1177/183335831504400104 
Submit or recommend next manuscript to OALib Journal and we will provide best service for you:

- Publication frequency: Monthly

- 9 subject areas of science, technology and medicine

- Fair and rigorous peer-review system

- Fast publication process

- Article promotion in various social networking sites (LinkedIn, Facebook, Twitter, etc.)

- Maximum dissemination of your research work

Submit Your Paper Online: Click Here to Submit

Or Contact service@oalib.com 